Excision of the Head of the Femur.

I now come to the operation which has engaged my special attention for some time past. Excision of the hip-joint or cxcision of the head of the femur has for a long time been one of the standard operations of surgery for many affections. Of late years it has fallen into disrepute, and deservedly so, for as performed in the old manner with complete lack of correct after-treatment the usual end-result was an unstable pathological dislocation. The operation flourished in the surgical enoch of excision of joints when surgeons were primarily concerned with the eradication of disease and operations were less commonly conceived in terms of function. The operation here designated "excision of the head of the femur," as applied to osteo-arthritis of the hipjoint and carried out in tlie manner to be described, is a somewhat different proseeding. It is fundamentally reconstructive, and not destructive, in type.

In brief, the operation involves the following steps: $(a)$ The removal of the overhanging mushroomed portion of the femoral head, leaving the stump of the neck of a reasonable length and with a slightly expanded upper end rounded off so as to simulate a new head; $(b)$ the stump of the neck is brought deeply into the acetabulum by fully abducting the limb; (c) the great trochanter, which has been detached as an integral step in the exposure of the hip-joint, is reattached to the femoral shaft at a lower level, thus acquiring a position of mechanical advantage (Figs. 1 and 2). This latter mancurre is an important feature of the operation. I have used it only in my later operations and before $I$ was aware that it had been already introduced by Royal Whitman of Now York as part of lis reconstructive operation on the hip for old fractures of the neck of the femur. There are other technical details of importance and interest. In removing the femoral head it is necessary to use a wide osteotome with a curved shaft in order to reproduce the rounded stump of the neck. The surface of the cancellous tissue thus exposed, after being smoothed off by filing, is thoroughly impregnated with Horsley's wax. The same procedure is carried out in the raw area left by the detachment of the trochanter. In addition, this latter area is covered by a small aponeurotic flap elevated from the vastus externus and turned upwards, leaving bare the femur in the region where the trochanter is to find its new site. With regard to the approach to the hip-joint used in this operation, in my experience the posterolateral roule described by Brackett ${ }^{2}$ is of all methods the most adequate.

After the operation the patient is nursed for six weeks on an abduction fiame; the hip is completely immobilized by means of a fixed extension for the first three weeks only; atter that gentle massage and active movements through a small range are given each day. In the intervals of treatment the patient is encouraged to repeat the attempts at active movement, the foot now being anchored to the lower part of the frame by a slack clove-hitch bandage. At the expiration of the six weeks' recumbency, if the patient has moved the hip with fair comfort (and this is usual), a calliper walking splint is applied and he is allowed to get up on crutches. A few weeks later full weight is borne on the calliper ring and the crutches discarded. 'The physiotherapeutic treatment is continued for some months, and the calliper splint is retained for at least six months; but in my experience the hip.joint is stable after three months, and the natural tendency of the patient is to discard the calliper at an early date.

The operation here described has given me exceedingly gratifying results, and for this reason has been described in some detail. I believe that it is applicable for the relief of the pain or malposition in moderately advanced cases of osteo-arthritis of the hip.joint at any age, provided the patient is constitutionally fit to undergo a major operation. There are few mechanical difficulties in the way of its fairly rapid performance; it takes less time and is less provocative of shock than an efficiently carried out arthrodesis. It is thus specially suitable for older patients, but my own trend at the present time is in favour of utilizing it also as an alternative to arthrodesis in younger individuals. The operation appears to give complete relief from the intolerable pain, and it also ensures the correction of the malposition. The degree of mobility in the reconstructed joint varies in different cases and under the influence of many factors. To some extent the range of mobility depends on the amount of bone removed in the resection of the femoral head-a factor which, as is well known, so often determines the function of any joint excision or arthroplasty. In a few individuals the range of mobility, which is free in the early days after the operation, later diminishes very considerably, but this, happily, is not associated with any return of the old pain and discomfort.

It is not suggested that this operation is in any way original either in its conception or its application, but a somewhat intimate acquaintance with the technicalities involved in its performance and personal experience of its effectiveness have urged me to emphasize its place in the repertoire of surgical procedures available for osteo-arthritis of the hipjoint.

1 Arta Med. Scandinavica, RTFERENCFs.

(1), fasc. ii. 2 Boston Med. and St:rg. Journ. February 5th, 1912.

\section{THE ETIOLOGY AND TREATMENT OF}

\section{DIABETES :}

With Special Reference to the Significance of a Starchsplitting and ACetone-forming Organism Found in the Stools of Diabetic Patients.

BY

ARNOLD RENSHAW, M.D.LoND., D.P.H.,

LECTORER IN PATHOLOGY, MANCHESTER UNIVERSITY; BACTERIOLOGIST. ROYAL EYE HOSPITAL, MANCHESTER; AND HONORARY PATHOLOGIST, ANCOATS HOSPITAL, MANCHESTER ;

AND

\section{THOMAS H. FAIRBROTHER, M.Sc.VIct.}

In the consideration of the pathology of diabetes very little is known concerning the source of the acetone bodiesacetone, diacetic acid, and beta oxybutyric acid-which are eliminated from the body in this disease, and which are considered to be the cause of the acidosis and coma which result from their accumulation. The generally accepted view is that these bodies are derived from the amino-acids of the protein molecule, from the fats of the tissues, or even from carboliydrates, but the tendency is rather to explain their origin trom the oxybutyric acid derived from fats.

In other words, there is general confusion on this point, and Adami correctly focuses present-day knowledge concerning them when ho says, "we cannot as yet say definitely what is the origin of these bodies, whether from the amino-acids of the protein molecule; from the fatty acids, or from the carbohydrates." No one has, so far as is known, laid down any experimental proof that these bodies may be derived from the carbohydrates by bacterial action within the alimentary canal.

Bacteria capable of producing acetone from starch or other carbolydrates have been known to exist for some time; thus in 1905 Schardinger ${ }^{1}$ first described such organisms. Secondly, under the name of "Amylobacter," Bredemann, ${ }^{2}$ in 1909 , described acetone-producing bacteria possessing spores. In this country attention was called to the practical application of these bacteria to industry by Fernbach and Strange ${ }^{3}$ (Eng. Pat., 1912, No. 21,073), who actually manufactured acetone on the commercial scale by the ferment action produced by those bacteria on starchy foods.

It is known that the acetone production from starch is not restricted to the action of one particular bacterium, but it is very likely that there exists a family of the bacteria which have been described generically as "Amylobacter." The difference between the members of the family is not com. pletely understood yet, but there are distinct differences in size-particularly in the width of the different organisms. Chemically, the point of similarity seems to be acetone production, which is common to all, and the point of difference the nature of the alcolol produced along with the acetone. Thus Fernbach's organism produces acetone and butyl alcohol, and this was developed during the war by Dr. Weizmann on account of the value of these two products, the one as a solvent for gun-cotton, and the latter for its use in connexion with isoprene, an intermediate body in the synthesis of india-rubber. In addition to this there is a complete description in the literature of another organism, B. acetoethylicum, described by Northup, Ashe, and Senior. This organism produces 10 per cent. acetone and 25 per cent. ethyl alcohol and small quantities of propyl and butyl alcohol. It is a much thinner organism than the one described, by Fernbach, being only 0.2 to $0.3 \mu$ against 0.8 to $1.0 \mu$.

A description of the acetone-butyl alcohol fermentation from starch and its technical application is given by Gill ${ }^{5}$ and a description of the organism was published by Thaysen ${ }^{6}$ in 
1921. The attention of the authors was drawn to this process in 1919, and the similarity of the products formed by it with those found in diabetes at once suggested to them the possibility of the organism being connected with this disease. 'Two differences were noted: in diabetes glucose was also present in the urine in addition to the acetoue bodies; and in the case of the organism the result of fermentation yielded also butyl al zohol.

It appeared probable, however, that the products of such a fermentation in the alimentary canal by this or a similar organism might upset the glyccgenic function of the liver, resulting in the excessive accumulation of glucose in the blood, with a consequent overflow elimination by the kidneys as soon as the blood sugar content became too high. It was further highly probable that the butyl alcohol or other alcohol formed during the course of such a fermentation could be oxidized in the liver so as to avoid elimination as such by the lidneys. 'This substance might, in fact, be the cause of the pigmentary cirrhosis of the liver sometimes met with in diabetes. It was resolved therefore to examine the stools of diabetic patients for the presence of an acetone-producing organism of the Amylobacter group, and attcmpts were begun in 1919 to isolate such a bacillus and to obtain ultimately a typical acetone fermentation therefrom. At the time these experiments were started very little information was avail. able to the authors regarding methods of cultivating the organism, and successive publications had to be studied to giean a knowledge of tl:e conditions required for a typical fermentation to be carried to a successful completion. The presence of such an organism in the stools of diabetic patients was quickly detected, and this organism produced a certain amount of gas and set up a fermentation in starch media. Films of these cultures showcd the presence of a sporeforming bacillus very similar to the organism described as B. amylobacter by Fernbach, and described by Gill in 1919 . A recent case of diabetes in a very young girl presented a very favourable opportunity for obtaining such organisms in greater numbers than were obtainable in older patients where the disease is of more chronic type.

The results of the present investigations show that in each of five cases we have isolated from the stools of diabetic patients an organism which is capable of p:oducing acetone, $\mathrm{N}$ butyl alcoliol, beta oxybutyric aciỏ, and diacetic acid. The acetone and alcolol are present, as will be seen, in large quantity in good fermentations. Further, an analysis of the stools of these patients has been made and acetone has been rccovered from the stools to a certain extent.

'In view of the ready absorption of acetone by the blood, the full fermentation yield of acetone cannot be expected in the stool as passed per rectum; but the presence of this substance in the stool, together with the presence of an acetoneproducing organism, would point to the alimentary canal as t? so source of intoxicatiou in diabetes. This fact is significant whien it is remembered that the organism flourishes best in carbohydrate media, and that carboliydrate foods are contraindicated in diabetes. The further description can best be considered as follows:

\section{Me!hods and Media Used.}

The following media were used:

Cu'ture Medium A (Semifluidl)-Quantities: Ground rice 54 grams, fine oatmeal 6 grams, water to make $1,000 \mathrm{c.cm}$. The rice and oatmeal are fed slowly into warm water with good stirring. Care should be taken to avoid lamps. Bring to the boil and leep at the hoil for a short time to ensure that the starch is gelatinized. Make up to volume and tube out. Sterilize for two hours at $30 \mathrm{lb}$. pressure.

Alternatice NIedium (Semifluid).-- Quantitics: Ground maize 60 grams, made up to $1,0.0 \mathrm{c.cm}$. of mash with water. 'The nethod of making up is the same as above. The important part is to have the material finely ground and to see that the mash is perfectly homogeneous, otherwise sterilization is difficult. For weaker strains better progress may be made with a 4 or 5 per cent. mash made up in the same way.

Culture Medium B (Solid). - First make up 1,003 c.cm. wort. Mash 100 grams of finely ground maize (or 90 grams of ground rice and 10 grams of oatmeal) with water to make up 1,C00 c.cm. After boiling for fifteen minutes cool to $60^{\circ} \mathrm{C}$. 'Add 10 grams of ground boiling for fitteen minutes cool to $60^{\circ} \mathrm{C}$. Ad all grams of ground bring to the boil for fifteen minutes to lsill the diastase. To this and 10 grams of gelatin, 10 grams of calcium carbonate, and 20 grams of agar. Heat gently to bring these into solution, then filter. Tube out and sterilize for one hour at $15 \mathrm{lb}$. pressure.

Melhod of Irolation.

The stool from the patient is emulsified with sterile water or saline. If two or three days old this emulsion will contain spores, and it can be pasteunrized for fif:een minules at $75^{\circ} \mathrm{C}$. before inoculating into Nedium A. If fresh, it is preferable to inoculate direct without pasteurizing. In any case heavy incculations of the stcol should be made by means of a sterile pipette to the bottom of the tube containirg Medium A. These are then incubated for one to three days. Gassing may or may not result, but the medium should become rather more liquid even in impure cultures. Spores will now have formed, and pasteurization may be carried ont for ten to twenty minutes, at $75^{\circ}$ to $80^{\circ} \mathrm{C}$., when cortions of the for ten to twenty minutes, at $75^{\circ}$ to $80^{\circ} \mathrm{C}$., when rortions of the
culture are diluted in sterile saline. It is preferable now to mix them in culture Medium B so as to isolate separate colonies. 'I'his medium should be melted and then cooled to $42^{\circ} \mathrm{C}$. before admixture of the dilutid pasteurized growth $f r c m$ the previous incubation, the medium being poured before solidification into sterile glass tubes 6 by 1 fitted at each end with sterile rubber stoppers. (These tubes should have been plugged with wool at each end and sterilized, the stoppers having besn antoclaved.)

When solidified the incculated tubes are incubated until growth When solidified the incculated tubes are incubated until growth occurs and the medium is split by the gas formation, which occurs
round the colonies of the acetone-producing organisms or other bacteria. The tube is then uncorked at one end, warmed to allow the solid medium to slide out into sterile Petri dishes, and then cut up into slices, ecrapings obtained from the different colonies being inoculated into tubes of Medium A. These tubes should now contain the organism in pure culture, and further fermentation should proceed at a more rapid rate. In -view, however, of the small amount of iname may elapse before even slight fermentation is visible; but when may elapse before even slight fermentation is visible; but when heavily into several tubes. T'wo or three tubes at least of an act.vely growing culture obtained as above should be then inoculated into a warm flask of the starch medium containing one litre of 6 per ccnt. mash. (Approximately $50 \mathrm{c.cm}$. of actively growing incculum are required for one litre of mash.)

The flasks should be incubated until fermentation is completed, usually thirty-six to forty-eight hours being required in a good fermentation. The contents of the flask are then distilled and the distillate examined quantitatively for acetone and butyl alcolnol, and qualitatively for diacetic and oxybutyric acids. The presence of a good fermentation is re. presented visibly by the evolution of a consiclerable amount of gas, which consists of $\mathrm{CO}_{2}$ and $\mathrm{H}_{2}$. This may be so iuspisated mas being split up by the diastatic ferment liberated by the growth of the bacillus, and a clear watery fluid forms in which masses of partialty digested starch may be carried up to the surface, there to form a head in the tube or flask. This head later sinlis and a clear supernatant watery fluid remaius.

In the above method, if it is desired to dispense with the solid medium in the anaerobic tube, the only other method available is to take a number of tubes containing high dilutions of the bacteria and to attempt, by repeated pasteurization, incubation, and dilution, to obtain the organism in pure culture.

It cannot be too clearly indicated, however, that there are numerous impuritics which will prevent the fermentation from being carried out, and the only way in which good fermentations can be obtained is apparently by the simul. taneous growth in masses of large numbers of the organisms. Reference will be made to these impurities later in regard to treatment. It is probably only on account of the presence of other bacterial impurities in the food within the alimentary canal that diabetes is not a more rapidly fatal disease-these impurities lowering the yield of acetone bodies which would otherwise be formed. Further, the great difficulty of carrying through a fermentation in vitro from sucl highly infected material as facces cannot be too clearly indicated.

\section{Description of Organism:}

The organism isolated is a Gram-positive rod-shaped bacillus and is a facullative spore-forming auaerobe. The bacillus is usually straight, 4 to $6 \mu$ in length, and about 0.9 to $1.2 \mu$ in thickness. The ends are slightly rounded. It may occur singly or in chains of two to six organisms, or the forms may lie parallel, two or three parallel forms being fairly commen, and parallel forms may be present even wher the members are existing in cluain formation. It is possible that this may represent fission in two planes-longitudinal and transverse. Young cultures are slightly motile, and in forms more than twenty-four hours old central spores may develop. The spores are oval in shape, protrude beyond the width of the bacillus, do not take the Gram stain, and usually have a small vestige of bacillary protoplasm left at cach end. This vestige tonds ultimately to disappear in older spores. The bacilli take basic stains, being well stained by carbol fuchsin ( 1 in 10), and less definitely stained by methylenc-blue. The Gram staining in young forms is quite definite. We suggest that the term Bacillus amyloclinsticus intestinalis be applied to the organism as found in the intestine of man. 


\section{Result of Fermentations.}

By the activity of the organisms proteolytic and diastatic enzymes are liberated. The diastatic enzyme, by its action, splits up starch; the proteolytic enzyme is manifest by the slight liquefaction of gelatin which occurs round the site of the colonies produced in Medium B. The organism develops best under anaerobic or partially anaerobic conditions, these conditions being satisfied when cultures are inoculated to the bottom of the tubes or flasks containing a well-gelatinized mash. In order to obtain an active fermentaticn of starch it appears necessary for a liberal amount of inoculum to be added (up to 5 per cent. of the tube or flask to be inoculated), since the fermentation appears to be retarded and even suppressed unless a large mass of organisms is growing simultaneously in one part of the medium. It is not, therefore, a good method to disseminate too freely the inoculum added.

The bacilli require a small quantity of protein with their starch, but experiments in hand appear to show that peptone can be substituted for protein, although it was at one time considered that peptone would not suffice. (See also Journ. Biol. Chem., 1919, 39, 1-21.)

If the reaction of the mass is taken in which fermentation is actively proceeding it is found to rise rapidly, ultimately alling on completion as follows:

1. Before incubation $10 \mathrm{c.cm}$. of mash required $0.3 \mathrm{c} . \mathrm{cm} . \mathrm{N} / 10$ $\mathrm{NaOH}$ to neutralize.

2. After twenty-four hours $10 \mathrm{c.cm}$. of mash required $3.96 \mathrm{c.cm}$. $\mathrm{N} / 10 \mathrm{NaOH}$ to neutralize.

3. After forty-two hours $10 \mathrm{c.cm}$. of mash required $2 \mathrm{c.cm}$. N/10 $\mathrm{NaOH}$ to neutralize.

In addition there is a considerable evolution of gas, which is found to consist of hydrogen and $\mathrm{CO}_{2}$. The estimation of the acidity can be regarded as indication of the progress of fermentation.

\section{Examination of Products of Fermentation.}

The signs of completed fermentation are cessation of gas evolution, and no further fall in the acidity of the liquor. The final acidity in a normal fermentation is such that $10 \mathrm{c.cm}$. of the mash require 1.8 to $2.5 \mathrm{c.cm}$. of $\mathrm{N} / 10 \mathrm{NaOH}$ for neutralization. (Boil off dissolved $\mathrm{CO}_{2}$ before testing the acidity, and use phenolphthalein as an indicator.) The mixture of acetone and alcoliols is referred to as mixed oil, and the estimation is carried out as follows:

The plug of the flask is removed and replaced by a stopper carrying a tube to a condenser, and the mash is distilled until no further oily drops are noticed in the condenser. Usually this distillate is 10 to 15 per cent. of the total volume in the first flask. The distillate is saturated with common salt and redistilled until The distillate is saturated with com

The second distillate is saturated with anhydrous potassium carbonate and poured into a measuring cylinder. The potassium carbonate solution settles to the bottom, and there is a very definite dividing line between this and the layer of oil. The volume of mixed oil obtained is read off on the cylinder. (If preferred, it may be separated in a separating funnel and weighed in a closed bottle.)

For estimation of the acetone in the mixed oil, the latter must be diluted to a suitable strength. If $25 \mathrm{ccm}$. of iodine are used in the iodoform estimation the amount taken should contain about 0.01 gram acetone. For example, if the mixed oil contains approximately one-third its weight of acetone, $10 \mathrm{c.cm}$. are taken and made up to $100 \mathrm{c} . \mathrm{cm}$. Then $10 \mathrm{c.cm}$. of this dilution are taken and made up to $250 \mathrm{c.cm}$., and $10 \mathrm{c.cm}$. of this last dilution will contain approximately 0.01 gram of acetone, and it is the amount used for titration.

Take $10 \mathrm{c.cm}$. of this diluted liquor, add $25 \mathrm{c.cm} . \mathrm{N} / 10$ iodine solution and $6 \mathrm{c.cm}$. of 20 per cent. $\mathrm{NaOH}$ solution; allow to stanc for five minutes then add 6 c.cm. of 20 per cent. HCl and titrate for five minutes, then add 6 c.cm. of 20 per cent. $(\mathrm{N} / 10)$. This gives the amount of iodine not used in the making of iodoform from the the amount of iodine not used in the making of iodoform from the the amount of iodine used; $1 \mathrm{c.cm}$. of $\mathrm{N} / 10$ iodine is equivalent to 0.000967 gram acetone.

Results of Case Examination.

The results obtained in cases in which fermentation was carried to completion were as follows:

Urine Examination.

\begin{tabular}{|c|c|c|c|}
\hline Patient. & $\underset{\text { (Grams per Litre). }}{\text { Sugar }}$ & Diacetic Acid. & $\begin{array}{c}\text { Acetone } \\
\text { (Grams per Litre). }\end{array}$ \\
\hline Ma. & 45.4 grams & Present & 0.72 gram. \\
\hline Ho. & 40.5 & Present & 0.047 \\
\hline Wa. & $20.0 \quad 10$ & Large amount & $0.057 \ldots$ \\
\hline Ba. & 42.7 & Present & 0.70 \\
\hline Ex. & 30.0 & Present & 0.25 \\
\hline
\end{tabular}

Stool Examination.

\begin{tabular}{c|l|l}
\hline Patient. & $\begin{array}{c}\text { Acetone in Stool as Per- } \\
\text { centsge on Dry Stool. }\end{array}$ & General Remarks as to Bacterio- \\
Ma. & 0.06 per cent. & $\begin{array}{l}\text { B. amyloclasticus intestinalis pre- } \\
\text { sent; also a long. thick bacillus } \\
\text { from which it had to be freed by } \\
\text { repeated pasteurization and sub- } \\
\text { culturing. }\end{array}$ \\
Ho. & $\begin{array}{l}\text { 0.c43 ner cent. with in } \\
\text { addition acetone bodies } \\
\text { equivalent to 0.02 per } \\
\text { cent. crotonic acid } \\
\text { Not examined } \\
\text { Wa. amyloclasticus intestinalis found. }\end{array}$ & $\begin{array}{l}\text { B. amyloclasticus intestinalis found. } \\
\text { Ba. }\end{array}$ \\
Br. & $\begin{array}{l}\text { 0.03 per cent. } \\
\text { B. amyloclasticus intestinalis. }\end{array}$ \\
\hline
\end{tabular}

Fermentation on Starch Media by Organism Isolated from Stool in each Case.

Final acidity of mash being approximately 2 c.cm. N/10 NaOH to neutralize $10 \mathrm{~cm}$. in each case.

\begin{tabular}{|c|c|c|c|}
\hline Patient. & Mixed Oil Products. & $\begin{array}{l}\text { Percentage } \\
\text { Weight of } \\
\text { Acetone on } \\
\text { Starch. }\end{array}$ & Nature of Oils. \\
\hline Ma. & $\begin{array}{l}20 \text { c.cm. on } 55 \mathrm{gm} . \\
\text { starch and } 5 \mathrm{gm} . \\
\text { oatmeal }\end{array}$ & 9.2 & $\begin{array}{l}\mathrm{N} \text { butyl alcohol equiva- } \\
\text { lent to twice amount }\end{array}$ \\
\hline Ho. & $\begin{array}{l}17.2 \text { c.cm. on } 54 \mathrm{gm} . \\
\text { starch and } 6 \mathrm{gm} . \\
\text { oatmeal }\end{array}$ & 6.8 & $\begin{array}{l}\text { Diacetic acid and } N \\
\text { butyl alcohol present } \\
\text { Trace of i so-b ut } 1\end{array}$ \\
\hline Wa. & 9 c.cm. on $25 \mathrm{gm}$. & 6.6 & acetone and $\mathrm{N}$ butyl \\
\hline Ba. & $\begin{array}{l}13 \mathrm{c.cm} \text {. on } 50 \mathrm{gm} \text {. rice } \\
\text { and } 5 \mathrm{gm} \text {. oqtmeal }\end{array}$ & 5.8 & $\mathrm{~N}$ butyl alcohol and \\
\hline Br. & $\begin{array}{c}10 \text { c.cm. on } 27 \mathrm{gm} \text {. rice } \\
\text { and } 3 \mathrm{fm} \text {. oatmeal }\end{array}$ & 5.2 & $\begin{array}{l}\text { Acetone; } \mathrm{N} \text { butyl al- } \\
\text { colool: trace iso-butyl } \\
\text { alcohol. }\end{array}$ \\
\hline
\end{tabular}

The alcohols were identified by preparing the 3.5 dinitro-benzoyl ester. and examination of the same.

Altogether nine cases of alleged diabetes have been under examination. Of these, five have been completed, and the results are indicated in the tables. The remaining four are receiving further experimental work. The organism has been detected microscopically in two of the remaining cases, but with it foreign organisms, which have retarded its action in the complete massive fermentation of starch, and great difficulties have been met with fermentation of starch, and great difficulties have been met with dication that in a short time these difficulties will be overcome and that the experimental results can be added to the five reported cases. Of the other two, one shows glycosuria following emotional disturbances, and the other is a young child now rendered sugar. free. As controls, eleven non-diabetic stools have been examined, and the organism has not been detected in any case.

Occurrence of Similar Organisms in Nature.

The acetone bacillus which was used during the war was beliered to occur on decaying maize, on bad potatoc $s$, and on other decaying vegetable matter. Northup isolated $B$. aceto. ethylicum from bad potatoes. Jute retting is supposed to be due to a similar organism, and in this respect the incidence of diabetes in Dundee amongst jute workers is highly suggestive of a bacterial infection by our bacillus. Occurring as it does on decaying vegetable life it is easy to understand how such a heat-resistant; spore-forming organism should enter the alimentary canal of liuman beings. It is probable that, if this be so, one of the post-war effects will be a considerable increase in the incidence of diabetes and of acidosis.

Discussion of Results with a View to Treatment.

The degradation of the complex starch molecule probably occurs by the formation of fatty acids with large molecules and then successive oxidation of two carbon atoms at a time, starting in the beta carbon atom. Ultimately, through the stage of intermediate fatty acids, the four-carbon fatty acid (butyric acid) will be arrived at. Oxidation will proceed normally at the beta carbon atom, producing the beta oxybutyric acid; this is capable of further oxidation at the same point to aceto-acetic acid, and this will be ultimately broken up, giving acetone and $\mathrm{CO}_{2}$. The changes can be followed by means of the following formulae:

\begin{tabular}{|c|c|c|c|}
\hline $\mathrm{CH}_{3}$ & $\mathrm{CH}_{3}$ & $\mathrm{CH}_{3}$ & $\mathrm{CH}_{3}$ \\
\hline $\mathrm{CH}_{2}$ & CH.OH & $\mathrm{C}=\mathrm{O}$ & $C=0$ \\
\hline $\mathrm{CH}_{2}$ & $\mathrm{CH}_{2}$ & $\mathrm{CH}_{2}$ & $\mathrm{CH}_{3}$ \\
\hline $\mathrm{COOH}$ & $\mathrm{COOH}$ & СOOH & $\stackrel{+}{\mathrm{CO}}{ }_{2}$ \\
\hline $\begin{array}{l}\text { Butyric } \\
\text { acid. }\end{array}$ & $\begin{array}{c}\text { Beta oxybutyric } \\
\text { acid. }\end{array}$ & $\begin{array}{l}\text { Aceto-acetic } \\
\text { acid. }\end{array}$ & $\begin{array}{c}\text { Acetore and } \\
\text { corbon dioxide. }\end{array}$ \\
\hline
\end{tabular}

* Since this article was prepared for press one of these two has given 
Thus it would appear that the beta oxybutyric acid and the accto-acctic acid produced in the course of the disease are intermediate products leading uitimately to acetone, providing the conditions are favourable. 'This conclusion is supported by the observations on the fermentation, where it is noted that the end of the reaction is determined by the fall in the acidity of the mash.

I'he fact that the alcohols produced in the fermentation arc not detected in the excreta of diabetic patients can be explained to some extent by their absorpition and possible oxidation in the liver to products which would not be easily detccted. Stepp ${ }^{7}$ claims that he has detected aldehydes (or substances which react in every way like aldehydes) in the blood of diabetic patients. Aldehydes would be the first products of the oxidation of normal alcolools, and complete oxidation would lead to $\mathrm{CO}_{2}$ and water. In endeavouring to obtain good yields of acetone the inlibitory effects of ccrtain bacteria came to be recognized. Thus Thaysen states that the organism which causes most damage to a fermentation is the $B$. volutans. Others have described the B. acidi lactici, and we have found the presence of a diplococcus and of a large thick bacillus, of unkuown identity as yet, to be respon. sible for much inhibition. It appears probable that these facts, combined with a diet so composed as to allow digestion and absorption by the patient of foods which the bacteria cannot assimilate, will prove an important part of treatment, combined with the administration of certain antiseptics. In this respect the authors ${ }^{8}$ wonld call attention to their work on the subject of antiseptic action amongst the coal-tar dyestuffs, which gives useful data as to the relative value of dyes as antiseptics in regard to different organisms.

Suminar.

1. From the stools of diabetics a new organism (B. amylo. clasticus inlestinalis) has been isolated which splits up starchy foods, forming oxybutyric acid, diacetic acid, butyl alcohol, aud acetone. Sugar is also formed during this fermentation.

2. Acetone has been found in quantities capable of estima. tion in the stools of diabetics.

3. In diabetes carbohydrate fermentation occurs in the alimentary canal, forming abnormal products which probably so affect the glycogenic function of the liver as to lead to iimproper storage therein of the glucose firom the alimentary canal during digestion.

4. Definite lines of treatment include elimination or sup. pression of this organism.

We wish to express our indebteduess for access to diabetic cases to Dr. J. Gray Clegg, Dr. Wm. Stirling, aud Dr. Laugley; and to Mr. A. Gill, B.Sc., for his technical assistance with the various processes herein detailed.

1 Schudinger: Centralbl. $f$ REFERENCES.

作, Bakteriol., 1905, 14, Abt. ii, 772. 2 Bredemann : Centralbl. f. Bakteriol. 1509, 23, Abt. ii. 3 Fernbach and Strange Chein. 1919, 39, No. 21.073). 4 Northup, Ashe, and Seninr: Journ. Riol. Joir.. of Society of Chemical. Ind Chem. 1919, 11, 723-27. 5 Amos Gill: pp. 273-80. 6 Thaysen: Joum, of Institute of Brewing vol xxvii, No. 11 . pp 529-542. 7 Stepp: Biochem. ZZtit., 107, 60-80 (1920) \& Fairbrother and Renshaw: Joun. of Path. and Bact., vol. $\mathrm{xxr}, 1922$, pp. 145-151.

\section{FRAGILITAS - OSSIUM ASSOCIA'TED WITH BLUE SCLEROTICS IN FOUR GENERATIONS.}

\author{
BY
}

\section{J. BROWNING ALEXANDER, M.D., M.R.C.P.Lond., \\ PHYSICIAN WITH CBARGE OF OCT-PATIENTS, PRINCE OF WALES'S \\ GENEHAL HOSPITAL, AND CITY OF LONDON HOSPITAL
FOII DISEASES OF THE CHEST.}

Instances of fragilitas ossium associated with blue sclerotics have from time to time appeared in medical literature, and as recently as December 24tl, 1921, Blegrad and Haxthausen of Copenhagen reported in the British Medical Journal cases showing, not ouly blue sclerotics and brittle bones, but also associated with macular atrophy of the skin and zonular cataract. Such cases are, however, sufficiently rare to warrant putting on record the following history:

The patient, F.F., aged $7 \frac{1}{2}$ years, presented himself at $\mathrm{my}$ outpatient department alout a year ago. The history was that he suffered from repeated fractures-the most recent having been one of the lower end of the right tibia. Some deformity was present in the right leg and the right thigh, and it was ascertained that both the tibia and the femur had been previously fractured-the latter having occurred at birth. In addition a history was obtained of past fractures of the left humerus and the tibia and fibula of the left leg. These had bealed with apparent perfect inion and minimal amount of callus. The most striking feature which one observed when the boy entered the consulting room was the marked blueness of bothi sclerotics. The chili was somewhat pale and debilitated, the forehead more promine it than normal, but no evidence of rickets was apparent. In other respects the morher stated that the boy had always been healthy. The mother, to whom the bor bore a strong resemblance, showed very deep blue sc'erotics. She had, however, no fractures. Her liearing was defective, and she informed me that she had sufferel from deafuess for many years. The patient's two sisters, whom I sa w later, also for many rears. The patient's two sisters, whom I saw later, also
presented blue sclerotics, with, however, no history of fractures. On inguiring further into the history of the family I found that the aunt of the patient (the patient's mother's sister) had sustained al together seven fractures during her life and had, as in the other menbers of the family, deep blue sclerotics. The grandmother and great-grandmother had both been the subjects of fragile bones and blue sclerotics. No further history of these phenomena was forthcoming in previous senerations to the ones alrealy mentioned; it is quite possible, however, that a careful studs of this family's genealogy would have revealed the same condition in former generations.

This remarkable association of brittle boines and blue sclerotics was first described by Eddowes in 1900, who suggested that " the transparency of the sclerotics indicated a want of quantity or quality of fibrous tissue forming the framework of the various organs of the body, and probably explained the want of spring or tonghness in the bones ot these individuals." 'The importance of heredity in these cases was most clearly indicated by Stephenson aud Harman in 1910, who published accounts of the same family of blue sclerotics-altogether 55 individuals in tire generations, 31 of whom showed typical sclerotics. No mention was then made of fragile bones; but in 1915 Stephenson showed at the Loudon Ophthalmological Society a mother and two daughters with fractures, belonging to this family. Rolleston, in 1911, reported 4 cases of blue sclerotics in three generations, with fragile bones occurring only in the third generation. Peters, in 1908, published the account of blue sclerotics in a family during three generations, and five years later furthes reported the occurrence of fractures in these cases. The interesting case reported by Ostheiner in the Journal of the American Medical Association of December, 1914, had blue sclerotics and nine fractures between the ages of $1 \frac{1}{2}$ and 4 years. In this case there was no history of the condition vccurring in other members of the family. The literature of the subject is further enhanced by the publication of similar cases by Burrows, in 1911 (a family of 29 indiriduals 13 with blue scleroties, and 9 of the 13 with brittle bones); Poynton, in 1913 ( 1 case); Hoffmann, in 1915 (3 cases); E. Bronson, in 1917 (description of two families); and Olaf Blegvad and Holger Haxthausen, Britrsh Medical Journal, December 24th, 1921.

There seems to be little doubt that the blueness of the sclerotics is due to the increased transmission of the colour of the choroidal pigment and not to any inherent colouring of the sclerotics themselves. Some think, however, that there is an actual thinning of the sclerotics. Fridenberg has suggested that the blue sclerotics are due to a transparency depending upon the absence of lime salts in the connective tissue of the sclera. The long-standing deafness in the case of the mother described is worthy of notice, and might. possibly be explained, as Bronson suggested, by a deposition of calcium salts in the middle ear, relating to the abnormal osteogenetic process.

\section{THE RECOGNITION AND TREATMENT OF MINOR DEGREES OF FIBROSI'TIS.} BY

THOMAS MARLIN, M.D., D.P.H., D.M.R.E., AsSistant ELECTRO- AND PHYSIO-THERAPEUTIST TO THE MIDDLESEX HOSPITAL.

KNowing the danger of missing an internal lesion which may be associated with superficial pain we naturally in such cases look for some objective sign. Failure to realize that the cause of many pains can be definitely detected in the soft tissues may explain why their examination is neglected. A patient who complains of pain in the region of the right scapula may be taken as an example. There may be some tenderness on pressure over a particular area, but otherwise nothing definite is noted; there is no swelling, no grating in the joints, and the lungs and heart are normal. The teeth may be surveyed and search made for some source of infec. tion or irritation, without finding anything to confirm the patient's statement. If, however, we now derote a little 